\title{
When the MAGIC stops: \\ magnesium in acute coronary syndromes \\ — a lesson in medical humility
}

Shannon Patrick, MD; ${ }^{*}$ Mel Herbert, MD, MBBS, BMedSci, FACEP, FAAEM ${ }^{\dagger}$

\begin{abstract}
There has been much debate as to whether magnesium, a well-tolerated, readily available and cheap therapy, should be used to treat patients with suspected myocardial infarction. Despite promising results from animal studies and small clinical trials conducted in the 1980s, two large recent trials have concluded that the once phenomenal treatment is ineffective. The story of magnesium for acute myocardial infarction is a lesson in medical humility.
\end{abstract}

Key words: myocardial infarction, therapy, magnesium

\section{RÉSUMÉ}

La question de savoir si le magnésium, traitement bien toléré, largement disponible et peu coûteux, devrait être administré aux patients chez qui l'on soupçonne un infarctus du myocarde, a suscité beaucoup de débats. Malgré les résultats prometteurs d'études sur des animaux et de petites études cliniques réalisées dans les années 1980, deux importantes études récentes ont conclu à l'inefficacité de ce traitement autrefois considéré comme phénoménal. L'histoire de l'utilisation du magnésium pour traiter l'infarctus du myocarde constitue une leçon d'humilité médicale.

\section{Background}

Physicians and researchers have long sought a safe, inexpensive, easily administered treatment that improves survival in acute coronary syndromes. Aspirin is all of these things; its low cost, incredible effectiveness and extreme safety make it the closest thing we have to a magical therapy for acute myocardial infarction (AMI). ${ }^{1}$ Despite mounting evidence to the contrary, many clinicians and investigators have clung to the belief that intravenous magnesium sulfate might rival aspirin as a therapy for ST-segment elevation AMI. ${ }^{2}$

The rationale for using magnesium to treat patients with
AMI derives from laboratory studies demonstrating that magnesium has anti-ischemic and cardioprotective effects. Magnesium is Mother Nature's calcium antagonist: a peripheral and coronary vasodilator with antiarrhythmic and antiplatelet effects that decreases reperfusion injury by preventing calcium overload in ischemic myocardial cells., ${ }^{3,4}$ Animal models of AMI suggest that magnesium limits infarct size if administered before or concurrent with reperfusion, but not if given after reperfusion..$^{5}$ Thus, magnesium infusions initiated shortly after the onset of myocardial infarction (MI) might be expected to limit infarct size, suppress life-threatening dysrrhythmias and improve prognosis. ${ }^{6}$

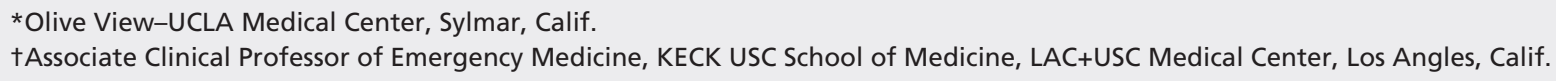




\section{The evidence}

Early data from more than 3600 patients were promising. Most notably, the 2316-patient LIMIT-2 (Second Leicester Intravenous Magnesium Intervention Trial) showed large and statistically significant decreases in mortality, heart failure and dysrrhythmia rates when intravenous magnesium was administered to patients with suspected AMI.7.8 Moreover, magnesium was associated with a $16 \%$ relative reduction (1.8\% absolute risk reduction) in all-cause mortality over a 2.7 -yr follow-up period $(p=0.03) .{ }^{9}$ Researchers concluded that the benefits seen in experimental ischemia-reperfusion models translated into real cardioprotective benefit in the clinical setting. As a result, many physicians incorporated magnesium sulfate into their AMI treatment protocols. ${ }^{10}$ Indeed, many educators on the CME circuit reprimanded clinicians who had not adopted magnesium as standard AMI therapy (Dr. Rick Bukata, Center for Medical Education, Creamery, Pa.: personal communication, 2003).

These encouraging results were later challenged, when the Fourth International Study of Infarct Survival (ISIS-4), a randomized trial of 58050 patients, reported no 5-week mortality benefit in patients treated with magnesium. ${ }^{11} \mathrm{Be}-$ cause of its large sample size, ISIS-4 was compelling, and the use of magnesium for AMI was largely abandoned; however, there were flaws in the study, and subsequent small trials again reported magnesium to be beneficial in MI patients, so the issue of magnesium's efficacy was not entirely resolved..$^{12-14}$

The most plausible explanation for the conflicting results of LIMIT II and ISIS-4 relates to differences in the timing of magnesium administration. Experimental evidence suggested that magnesium's cardioprotective effects are dependent on the presence of high serum magnesium concentrations at the time of reperfusion. In ISIS-4, magnesium was administered much later after symptom onset ( 8 hours, compared to 3 hours in LIMIT-2) and was administered after, rather than before or with, thrombolytic therapy. Magnesium supporters speculated that ISIS-4 subjects did not have sufficiently elevated plasma magnesium levels until after the myocardial protection time window had closed, thus negating any potential beneficial effects of magnesium. ${ }^{5}$

Another proposed explanation for the disparity between the earlier trials and ISIS-4 was the low overall mortality in the ISIS-4 trial. In the earlier trials, the benefit of magnesium increased as the control group mortality rate increased, and a more recent randomized trial demonstrated a substantial $79 \%$ reduction in mortality among high-risk patients receiving magnesium treatment (control group mortality rate of $17.3 \%) .{ }^{14}$ In ISIS-4, control group mortality rate was $7.2 \%$, significantly lower than previous trials, raising the possibility that most ISIS-4 patients were in a low-risk group unlikely to benefit from magnesium. ${ }^{15}$

\section{MAGIC}

The Magnesium in Coronaries (MAGIC) trial was a double-blind randomized clinical trial designed to resolve these controversies and to determine if magnesium therapy was efficacious for specified high-risk groups - patients over 65 years and those otherwise ineligible for reperfusion therapy with either thrombolytics or angioplasty. MAGIC randomized 6213 high-risk patients with suspected acute ST-elevation MI (STEMI) or new left bundle branch block to intravenous magnesium sulfate or placebo within 6 hours of the onset of symptoms. Magnesium was administered before reperfusion when appropriate, and all patients received other standard treatment for AMI.

At 30-day follow-up, mortality rates were $15.3 \%$ in the magnesium group and $15.2 \%$ in the placebo group (odds ratio $=1.0 ; 95 \%$ confidence interval, $0.9-1.2 ; p=0.96$ ). There was no evidence of benefit or harm in any subgroup, and the authors concluded that there was no indication for routine administration of magnesium in patients with STEMI. ${ }^{16}$

The MAGIC investigators commented that the null effect of magnesium was surprising given the results of previous trials, and the reasons for the lack of benefit were unclear. Some suggested that publication bias and small sample size may have inflated the apparent benefits seen in previous trials. Others speculated that magnesium's proposed cardioprotective mechanisms might overlap with those of current AMI therapies not routinely used in earlier trials, such as beta-blockers and angiotensin-converting enzyme inhibitors.

Whatever the reason for the disparate results, the cycle of over-optimism, disappointment, renewed enthusiasm and repeated disappointment is humbling. Many of us used magnesium and bullied others into using magnesium as routine therapy for AMI. Now, we academics are equally aggressively reporting magnesium's lack of benefit and suggesting it has no role in modern therapy. As of March 2004, magnesium is dead — at least as a therapy for AMI - but don't be surprised if it reappears. In an age of expensive, over-hyped "wonder drugs," the concept of a cheap, safe and effective therapy, not marketed by any pharmaceutical company, is more than some of us can resist. And one thing appears constant in medicine: Today's 
certainty is tomorrow's myth, and yesterday's myth is often tomorrow's reality. The trick is telling them apart.

Competing interests: None declared.

\section{References}

1. ISIS-2 (Second International Study of Infarct Survival) Collaborative Group. Randomized trial of intravenous streptokinase, oral aspirin, both, or neither among 17,187 cases of suspected acute myocardial infarction: ISIS-2. Lancet 1988;2:349-60.

2. Yusuf S, Flather M. Magnesium in acute myocardial infarction. BMJ 1995;310:751-2.

3. Ferrari R, Albertini A, Curello S, Ceconi C, Di Lisa F, Raddino $\mathrm{R}$, et al. Myocardial recovery during post-ischemic reperfusion: effects of nifedipine, calcium, and magnesium. J Mol Cell Cardiol 1986;18:487-8.

4. Woods KL. Possible pharmacological actions of magnesium in acute myocardial infarction. Br J Clin Pharmacol 1991;32:3-10.

5. Baxter GF, Sumeray MS, Walker JM. Infarct size and magnesium: insights into LIMIT-2 and ISIS-4 from experimental studies. Lancet 1996;348:1424-6.

6. Maxwell S. Emergency management of acute myocardial infarction. Br J Clin Pharm 1999;48:284-98.

7. Teo KK, Yusuf S, Collins R, Held PH, Peto R. Effects of intravenous magnesium in suspected acute myocardial infarction: overview of randomized trials. BMJ 1991;303:1499-503.

8. Woods KL, Fletcher S, Roffe C, Haider Y. Intravenous magnesium sulphate in suspected acute myocardial infarction: results of the second Leicester Intravenous Magnesium Intervention Trial (LIMIT-2). Lancet 1992;339:1553-8.

9. Woods KL, Fletcher S. Long-term outcome after intravenous magnesium sulphate in suspected acute myocardial infarction: the second Leicester Intravenous Magnesium Intervention Trial (LIMIT-2). Lancet 1995;343:816-9.

10. Yusuf S, Teo K, Woods K. Intravenous magnesium in acute myocardial infarction: an effective, safe, simple, and inexpensive intervention. Circulation 1993;87:2043-6.

11. ISIS-4 (Fourth International Study of Infarct Survival) Collaborative Group. ISIS-4: a randomized factorial trial assessing early oral captopril, oral mononitrate, and intravenous magnesium sulphate in 58,050 patients with suspected acute myocardial infarction. Lancet 1995;345:669-85.

12. Raghu C, Peddeswara RP, Seshagiri RD. Protective effect of intravenous magnesium in acute myocardial infarction following thrombolytic therapy. Internat J Card 1999;71:209-15.

13. Thogersen AM, Johnson O, Wester PO. Effects of intravenous magnesium sulphate in suspected acute myocardial infarction on acute arrhythmias and long-term outcome. Internat J Card 1995;49:143-51.

14. Shechter M, Hod H, Chouraqui P, Kaplinsky E, Rabinowitz B. Magnesium therapy in acute myocardial infarction when patients are not candidates for thrombolytic therapy. Am J Cardiol 1995; 75:321-3.

15. Antman EM. Randomized trials of magnesium in acute myocardial infarction: big numbers do not tell the whole story. Am J Cardiol 1995;75:391-3.

16. Antman EM and The Magnesium in Coronaries (MAGIC) Trial Investigators. Early administration of intravenous magnesium to high-risk patients with acute myocardial infarction in the Magnesium in Coronaries (MAGIC) Trial: a randomized controlled trial. Lancet 2002;360:1189-96.

Correspondence to: Dr. Mel Herbert; MelHerbert@ cbooth.com 